\title{
The Contribution of Environmental Impairment Liability (EIL) Insurance to Eco-Efficiency
}

\author{
by Peter Zweifel*
}

\section{Introduction}

The objective of environmental policy can be commonly defined to attain an optimal level of environmental quality, or - which amounts to the same thing - the optimal amount of environmental impairment. This also means that the level of environmental quality opted for should be reached at minimal cost. There are several ways to achieve this goal, raising the issue of the "right" mix of the instruments available. Rather than addressing this issue directly, this paper, starting from the observation that Environmental Impairment Liability (EIL) insurance exists and will continue to exist, asks whether the effectiveness of available instruments is positively or negatively affected by the presence of EIL insurance. In section 2, the impact of EIL on five instruments of environmental policy will be analyzed, (1) environmental standards, (2) internalizing taxes, (3) tradable permits, (4) environmental tort law, and (5) capital markets for risk shares. These instruments are ordered according to decreased regulatory intensity and increased closeness to market-driven processes. It will be found in section 3 that the contribution of EIL insurance to these instruments is the more promising the more market-oriented the policy instrument.

\section{Five instruments of environmental policy and EIL insurance}

\subsection{Environmental standards and EIL insurance}

At first sight, the relationship between environmental standards and EIL insurance appears to be one of antagonism. The moral hazard effects emanating from insurance are feared to undermine enforcement of environmental standards because the financial consequences of unlawful behavior do not fully fall upon the insured tortfeasor. For example, a chemical firm that has insurance against fines that would be imposed because of pollution

* Department of Economics, University of Zurich. This is the revised version of a paper given at the Policy Workshop, "Management Strategies for Eco-Efficiency and Cooperation" held at the Forum Ludwigsburg (Germany), 24-25 May 1995 and jointly organized by the Risk Management and Decision Research Center of the Wharton School and the Center of Technology Assessment in Baden-Württenberg. Critical comments by Howard Kunreuther (Wharton) and Jean-Robert Tyran (Zurich) helped to improve this paper.

Key words: Eco-efficiency, insurance, moral hazard, environmental policy. 
may well skimp on efforts at keeping the ground water in its neighborhood free of contamination. To eliminate this effect, general terms and conditions of insurance always exclude coverage of illegal activities of the consequences thereof.

However, there is an additional, more subtle effect. Environmental standards usually define a nonzero maximum allowable level of environmental impairment, thus creating a range of outcomes that may be legally covered by EIL insurance. In addition, standards are the result of a bargaining process between the government and the regulated industry. In this process, the presence of EIL insurance is likely to affect the behavior of both bargaining partners. On the one hand, government knows that EIL insurance will provide compensation to victims, which may serve to soften its stance. The same is true of the regulated industry, who can count on the protection afforded by EIL coverage (however, see the effect of experience rating discussed in section 2.5 below). Therefore, it is not clear at all whether EIL on balance causes an unwarranted relaxation of environmental standards.

Conclusion 1: The presence of EIL insurance covering the legally accepted range of environmental impairment has an ambiguous effect on the stringency of these standards when interpreted as the outcome of a bargaining process between government and regulated industry.

\subsection{Internalizing taxes and EIL insurance}

For a cost-minimizing firm, saving internalizing taxes constitutes the incentive to contain its impairment of the environment. By buying EIL insurance, it can show premiums paid as an increase in its cost of production, which may be used as an argument in the negotiation process surrounding internalizing taxes in the presence of international competition. Given the cost increase, a deferral of the introduction of or a reduction of the rate of internalizing taxes is likely to be considered as a nieans for restoring international competitiveness (however, see Jaffee et al. (1995)). Therefore, the firm may hope to obtain a tax offset by purchasing EIL insurance. EIL insurance thus appears to detract from the effectiveness of internalizing taxes.

This verdict changes once innovation and uncertainty are introduced into the picture. Specifically, the chemical firm may consider adopting an innovation that promises to reduce emissions and hence the amount of internalizing tax to be paid. If, however, the effectiveness of this innovation and hence the amount of tax relief to be reaped is surrounded by uncertainty, risk-averse managers may well decide against adopting it. On the other hand, EIL insurance, by reducing the tax burden at any rate, will also alleviate the uncertainty with regard to the tax savings to be expected from the innovation. Thus, EIL insurance may end up fostering financially risky innovations benefitting the environment.

Conclusion 2: In a static world, EIL insurance detracts from the effectiveness of internalizing taxes. Once innovations are introduced into the picture, EIL insurance may encourage innovations whose environmental and hence financial benefits in terms of tax savings are uncertain.

\subsection{Tradable permits and EIL insurance}

Tradable permits enable a firm to buy and sell rights to pollute. Thus, their market price at any time indicates the cost of ensuring that the maximum allowable global amount of pollution set by political decree is not exceeded. Quite likely, however, this market price will fluctuate over time, constituting a source of uncertainty. Risk-averse firms will therefore 
seek to hedge against the risk of having to buy rights at a high price in the future. One way to do this is to purchase insurance (which would amount to an extension of existing EIL coverage) against a shortfall in the number of (expensive) permits that would force a curtailment of production.

Conclusion 3: Extended EIL insurance unambiguously enhances the effectiveness of tradable permits as an instrument of environmental policy.

\subsection{Environmental tort law and EIL insurance}

It is in this domain that the impact of EIL insurance is most immediate. At first sight, the situation seems to be comparable to the case of environmental standards (see section 2.2 above), since an injurer becomes liable only if he exceeded a standard of pollution that is frequently set and adjusted by the courts. It may be argued that the presence of EIL insurance again invokes moral hazard, inducing a propensity to approach and even exceed the amount of impairment that is compatible with due care.

At this juncture, however, much depends on the insurer's premium setting policy. If the operates a well-developed experience-rated system, every EIL case has a (possibly increasing) price to the polluter (see Shavell (1987), ch. 10 for details). For example, the management of the chemical firm mentioned in section 2.1 above must take into account that it will have a higher EIL insurance premium on the books when causing pollution in excess of the legal standard.

Conclusion 4: Experience-rated EIL insurance holds the promise of enhancing the effectiveness of the tort law system as regards the environment.

\subsection{Capital markets and EIL insurance}

During the last few years, layers of insurance coverage have increasingly been put on capital markets, in particular the Chicago Board of Trade. In the future, firms facing very large risks (e.g. nuclear power plants) might float risk shares on capital markets. Investors would then trade off higher EIL risk against a higher rate of return on such risk shares. Since this return has to be paid by the issuer, the cost of coverage for catastrophic risks would be shifted to consumers rather than borne by governments (Environmental Risk Internalization through Capital Markets (ERICAM), see Tyran and Zweifel (1993) for details). Certainly, well-informed EIL insurers with their largely diversified portfolios would act as investors on such capital markets, enhancing their efficiency even more.

Conclusion 5:The presence of EIL insurance would serve to increase the effectiveness of capital markets as an instrument of environmental policy.

\section{Overview of findings}

The findings stated in Conclusion Nos. 1 to 5 of the preceding sections appear in table 1 below. The entries of the table show how the static effectiveness of the five policy instruments considered are affected by the presence of EIL insurance. These entries suggests that with increasing closeness to market-driven processes (being minimum for environmental standards and maximum for capital markets), the impact of EIL insurance becomes more favorable. However, static effectiveness is only one element in an assessment of eco-efficiency. Information requirements for meting out sanctions to agents failing to comply with the legal norm must also be considered. While the details are spelled out elsewhere 


\begin{tabular}{|c|c|c|c|c|c|c|}
\hline \multirow{5}{*}{ 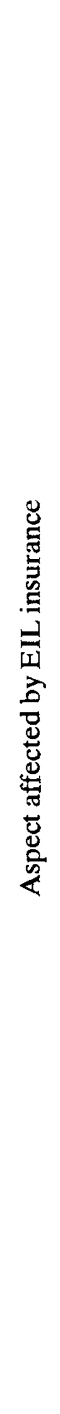 } & 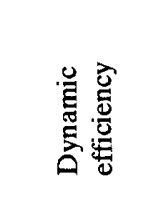 & 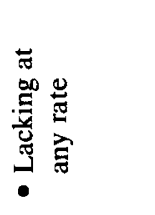 & 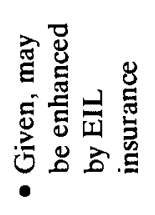 & 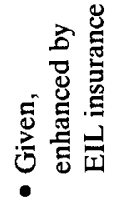 & 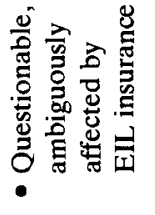 & 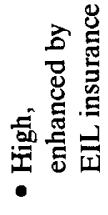 \\
\hline & 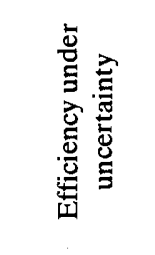 & 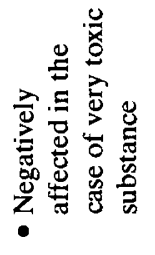 & 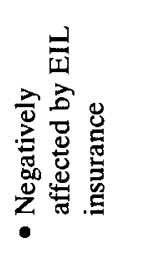 & 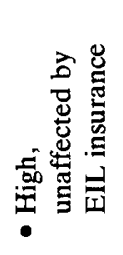 & 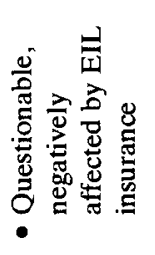 & 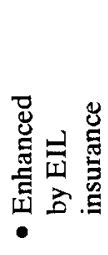 \\
\hline & 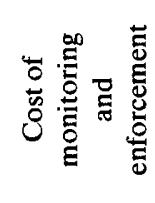 & 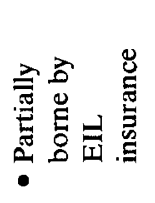 & 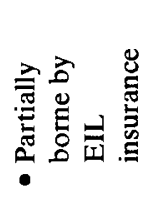 & 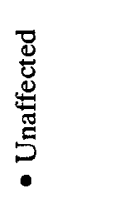 & 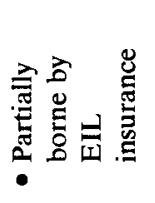 & 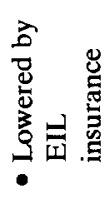 \\
\hline & 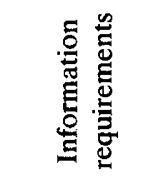 & 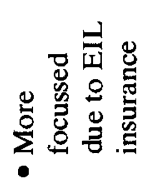 & 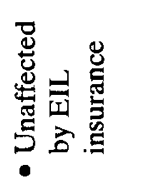 & 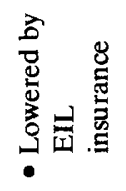 & 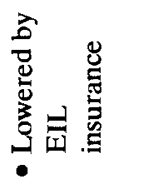 & 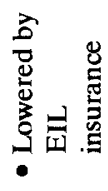 \\
\hline & 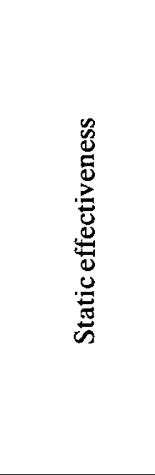 & 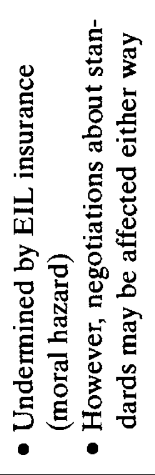 & 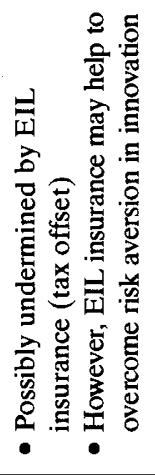 & 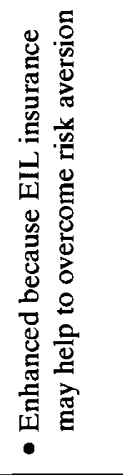 & 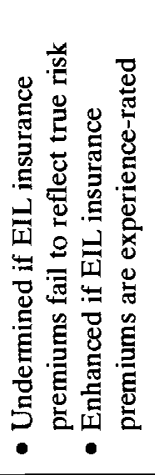 & 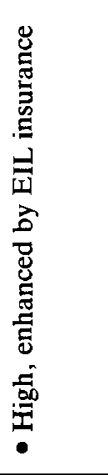 \\
\hline & 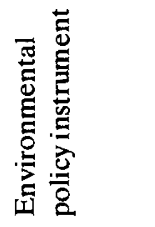 & 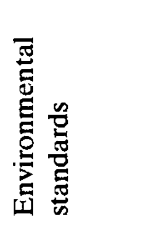 & 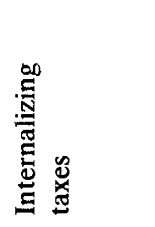 & 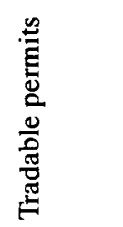 & 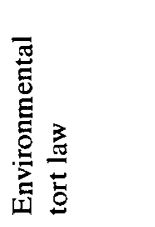 & 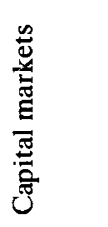 \\
\hline
\end{tabular}


(Zweifel and Tyran (1994)), EIL insurance may be said to bring about a more focused gathering of information, e.g. by encourageing audits. Next, there are costs of monitoring and enforcement, which are again taken over by EIL insurance to some extent. In addition, there often is the problem of uncertainty; specifically, the (marginal) cost of compliance may not be known precisely to the policy maker. As shown by Griffin and Steele (1986, p. 188), this may well militate against the use of internalizing taxes when the substance or process in question is very toxic. By cushioning the sanction, EIL insurance cannot but detract from the efficiency of environmental norms and internalizing taxes while the presence of knowledgable EIL insurers in capital markets helps to disseminate information.

Finally, dynamic efficiency, which reflects the speed of adoption of new technologies that are more beneficial to the environment, tends to be enhanced by EIL insurance.

Conclusion 6: When the criteria considered are extended beyond static effectiveness to include information requirements, cost of monitoring and enforcement, uncertainty, and dynamic efficiency, EIL is found to make positive contribution to eco-efficiency in most cases.

\section{Concluding remarks}

Claiming that EIL insurance always enhances the effectiveness of the instruments of environmental policy, thus foresting eco-efficiency, would clearly go too far. However, its beneficial contribution tends to become the stronger the more market-based the instrument considered is. Thus, the contribution of EIL insurance to eco-efficiency may grow in the future, especially if governments are willing to consider a wider choice of options for environmental policy. Even if EIL insurance were to fail to enhance effectiveness of any of the instruments considered, however, it should never be forgotten that availability of insurance as such is beneficial to both risk-averse victims and risk-averse potential tortfeasors.

\section{REFERENCES}

GRIFFIN, J. M. and STEELE, H. B., Energy Economics and Policy, New York: Academic Press, 2nd ed., 1986.

JAFFEE, A. B., PETERSON, S. R., PORTNEY, P. R. and STAVINS, R. N., Environmental Regulation and the Competitiveness of U.S. Manufacturing: What Does the Evidence Tell Us? in Journal of Economic Literature, 33 (March) 1995, pp. 132-163.

SHAVELL, S., Economic Analysis of Accident Law, Cambridge MA: Cambridge University Press, 1987.

TYRAN, J.-R. and ZWEIFEL, P., Environmental Risk Internalization through Capital Markets (ERICAM) : the Case of Nuclear Power, in International Review of Law and Economics, 13, 1993, pp. 431-444.

ZWEIFEL, P. andTYRAN, J.-R., Environmental Impairment Liability as an Instrument of Environmental Policy, in Ecological Economics, 11, 1994, pp. 43-56. 